\title{
O "efeito nefasto" da corrupção no Brasil: "quem paga mais?" Aplicações com o uso de regressões quantílicas com variáveis instrumentais
}

The 'detrimental effect' of corruption in Brazil: 'who pays more?' Applications using instrumental variable quantile regression

\begin{tabular}{|c|c|}
\hline Leonardo Andrade Rocha(1) & (1) Universidade Federal Rural do Semi-Árido \\
\hline Ahmad Saeed Khan (2) & (2) Universidade Federal do Ceará \\
\hline Patrícia Verônica Pinheiro Sales Lima ${ }^{(3)}$ & $\begin{array}{l}\text { (3) Universidade Federal do Ceará } \\
\text { (4) Universidade Estadual de Campinas }\end{array}$ \\
\hline Maria Ester Soares Dal Poz ${ }^{(4)}$ & (5) Universidade Federal Rural do Semi-Árido \\
\hline Fernando Porfírio Soares de Oliveira(s) & \\
\hline
\end{tabular}

\section{Abstract}

This study analyzes the impact of corruption on the dynamics of investment by Brazilian companies. For this, was employed a sample of 3,444 companies according to microdata available by the World Bank Enterprise Surveys. Using instrumental variable quantile regression estimator, the model results indicate that, in the absence of control due to endogeneity problems, the traditional estimator Koenker and Basset tends to underestimating the impact of corruption in reducing the elasticity coefficients of business investment. Firms located in the upper quantile of the conditional distribution of sales have better results in the implementation of investments even after the perceptual effect of corruption, unlike firms in lower quantiles. This suggests that firms with high performance are less "impacted" with the presence of corruption in relation to firms with poor performance.

\section{Keywords}

corruption; quantile regression; instrumental variables.

JEL Codes D73; C31; C36.

\section{Resumo}

O presente estudo analisa o impacto da corrupção na dinâmica dos investimentos de empresas brasileiras. Para isso, foi adotada uma amostra de 3.444 empresas conforme os microdados disponiveis pelo Enterprise Surveys do Banco Mundial. Usando o estimador de regressão quantílica com variáveis instrumentais os resultados do modelo apontam que, na ausência do controle devido aos problemas de endogeneidade, o estimador tradicional de Koenker e Basset tende a subestimar o impacto da corrupção na redução dos coeficientes de elasticidade dos investimentos das empresas. Firmas situadas nos quantis superiores da distribuição condicional das vendas apresentam melhores resultados na aplicação dos investimentos, mesmo após o efeito perceptivo da corrupção, ao contrário das empresas situadas nos quantis inferiores. Isso sugere que as firmas com elevada performance são menos "impactadas" com a presença da corrupção em relação às firmas com baixa performance.

\section{Palavras-chave}

corrupção; regressão quantílica; variáveis instrumentais.

Códigos JEL D73; C31; C36. 


\section{Introdução}

O tema corrupção tem sido debatido no mundo, destacando a fragilidade das instituições em circunstâncias nefastas ao desenvolvimento econômico, conforme pesquisa sobre o ambiente dos negócios em diversos países no mundo. ${ }^{1}$ No Brasil, de 1.802 empresários entrevistados 68,8\% afirmaram que a corrupção constitui um gravíssimo obstáculo para o desenvolvimento, contra 44,9\% na média da América Latina e 35,2\% no mundo. Além disso, 45,4\% identificam que a justiça consiste em um gravíssimo obstáculo para o desenvolvimento, uma percepção bem acima da média regional na América Latina (29,1\%) e mundial (15,5\%). Ferraz e Finan (2011) encontraram evidências de que prefeitos com incentivos à reeleição são significativamente menos corruptos em relação aos prefeitos sem incentivos de reeleição (sem chances de perpetuar seu mandato). Em níveis municipais, prefeitos "corruptos" ao final do seu primeiro mandato e sem chances à reeleição chegam a desviar aproximadamente US $\$ 55.000$ dos cofres públicos em relação aos prefeitos que alcançam a reeleição. No Brasil, esses custos somados podem chegar a uma cifra de US\$160 milhões.

Recentes pesquisas, destacando Ayyagari et al. (2014) e Jiang e Nie (2014), vêm sugerindo impactos negativos da corrupção, tomando em suas análises, séries financeiras de empresas. Embora seja um tema bastante abordado na literatura econômica, Asiedu e Freeman (2009) apontam para a escassez de estudos utilizando microdados. Essa situação leva a conhecimento mais restrito dos impactos da corrupção e da sua percepção na dinâmica dos negócios.

Conforme Ayyagari et al. (2014), o ambiente predatório mais propenso nas economias em desenvolvimento condiciona as firmas a pagarem volumes expressivos de propina para implementação dos seus projetos de investimentos. Nesse ambiente "adverso" as firmas inovadoras são mais afetadas, uma vez que os investimentos em P\&D (Pesquisa e Desenvolvimento) estão mais sujeitos a fatores de incerteza. As firmas inovadoras pagam maior volume de propina em relação às não inovadoras, de forma que a corrupção atua como uma taxação sobre essas atividades, aumentando os custos dos inovadores. Esse ambiente compromete o progresso tecnoló- 
gico em longo prazo. Além disso, a corrupção pode afetar a confiança nas instituições públicas e no próprio ambiente democrático.

Clausen et al. (2011) identificaram um efeito negativo e significativo da corrupção na confiança das instituições. Nas economias em que a percepção da corrupção é alta, o efeito adverso sobre a confiança é maior, em detrimento das economias com baixa percepção. Isso sugere que, nas economias em que a corrupção é um comportamento marginal no sistema, a prática do suborno não afeta substancialmente a "fé" sobre as instituições públicas, ao contrário das economias cuja corrupção torna-se mais estrutural.

Embora os efeitos nocivos da corrupção sejam bastante claros frente às pesquisas que abordam o tema, estudos alternativos vêm sugerindo uma direção contrária nessa relação. Duas importantes hipóteses destacam os efeitos da corrupção no crescimento: (1) a hipótese da "graxa na engrenagem"; e (2) a hipótese da "areia na engrenagem". Na primeira hipótese, as distorções causadas por instituições ineficientes podem conduzir os agentes a buscarem formas alternativas para "acelerar" a implementação de seus projetos de investimentos, envolvendo o suborno como forma de contornar os entraves da burocracia (Lui, 1985). Ao contrário disso, a corrupção consiste numa atividade que gera renda extra aos oficiais corruptos por meio de práticas ilícitas. Assim, os atrasos ocasionados pelos funcionários corruptos constituem uma oportunidade para extrair subornos. Nesse caso, a corrupção não consiste numa manobra benéfica para a atividade econômica, mas sim em uma consequência natural da atividade burocrática. Consequentemente, distorções no sistema vão se somando e caracterizando um efeito de "areia na engrenagem" (Meón; Weil, 2010).

$\mathrm{Na}$ presente pesquisa, as diferenças de desempenho entre as firmas condicionam o sentido dessa relação. Assim, firmas que operam com uma determinada performance defrontam-se com custos de oportunidade relativos em seus investimentos, tornando-as mais adaptáveis ou não ao ambiente "adverso" da corrupção. Esta reflexão torna a técnica tradicional de regressão imprópria para analisar o efeito da corrupção em diferentes pontos percentuais da distribuição condicional do desempenho da firma. Um método alternativo consiste na técnica de regressão quantílica. Essa técnica oferece maior precisão na análise da relação entre as variáveis, permitindo computar diversas curvas de regressão conforme diferentes intervalos da distribuição condicional. 
Contudo, essa técnica não apresenta problemas relativos à endogeneidade. Na presença de regressores endógenos, as propriedades de não tendenciosidade e consistência deixam de ser garantidas. Para solucionar esse problema, Chernozhukov e Hansen (2008) propuseram um estimador alternativo baseado na técnica de variáveis instrumentais. Essa abordagem controla a endogeneidade observada por meio de instrumentos trabalhados ao longo de cada quantil condicional.

A percepção da corrupção é condicionada a outras "falhas institucionais" que afetam sua compreensão por parte dos agentes, à medida que outras dimensões de governança potencializam ou não a definição de um ambiente propício às atividades predatórias (Lambsdorff, 2007). A ausência dessa compreensão no modelo pode conduzir a erros de medição que afetam diretamente no custo da corrupção percebida.

Poucos estudos analisaram os impactos da corrupção na economia brasileira numa dimensão em nível de microdados. Em especial, Ferraz e Finan (2011) estimaram o impacto da corrupção nos cofres públicos usando relatórios do programa de combate à corrupção da Controladoria Geral da União - CGU e implementado em auditorias municipais com relação à gestão de verbas federais. Os resultados revelaram que a corrupção é responsável por perdas na economica brasileira que equivalem ao montante de US $\$ 550$ milhões por ano. Diante da escassa literatura sobre o tema, a presente pesquisa teve como objetivo analisar o impacto da corrupção na dinâmica dos investimentos de empresas brasileiras.

\subsection{Definindo a corrupção e seus impactos}

O conceito mais popular sobre a corrupção tem sido definido como "o abuso do poder público para benefício privado" (Lambsdorff, 2007, p.16). Nessa definição alguns importantes pontos são levantados: primeiro, a concepção de "benefício privado" se refere à apropriação de recursos ou ativos privados por agentes públicos, visando à acumulação do capital ou manutenção do status ou poder. Segundo, o poder público é exercido por burocratas e por políticos, que usam do cargo para obter vantagens econômicas ilícitas em contratos públicos ou em barreiras à concorrência. $\bigcirc$ termo "abuso" compreende um comportamento que se desvia dos compromissos formais do serviço púbico, geralmente onde os interesses parti- 
culares são conduzidos à custa do interesse coletivo.

Conforme Kunicová e Rose-Ackerman (2009), a definição de corrupção como o uso indevido do cargo público para ganho financeiro privado contempla desde as atividades que levam ao enriquecimento financeiro pessoal de políticos e agentes aos casos em que os próprios políticos conduzem estratégias necessárias para obter apoio político. Conforme os autores, essa definição vem se tornando cada vez mais presente nos estudos comparativos, pois tem destacado o caráter "nefasto" da corrupção na economia.

Entre as consequências da corrupção podem-se destacar: redução da eficiência operacional das firmas, distorções da ordem pública, apropriação da renda, queda da confiança nas instituições, falta de transparência, instabilidade política, entre outras (Godinez;Liu, 2015). Embora tais aspectos negativos ("areia na engrenagem") sejam predominantes em uma ampla literatura, ${ }^{2}$ outros estudos vêm apresentando uma visão diferente nesses resultados.

Segundo Meon e Weill (2010), a ineficiência que a burocracia pode causar, por vezes, é compensada com um nível adequado de corrupção que funciona como uma lubrificação no sistema econômico. Essa hipótese é definida como "graxa na engrenagem" e está associada a uma dinâmica específica que depende de propinas e subornos para dar andamento a projetos de investimentos em determinadas economias. Assim, em instituições ineficazes a hipótese de "graxa" pode conduzir a ganhos de eficiência nos investimentos. Ambas as hipóteses preveem a redução na eficiência em um ambiente institucional desenvolvido (eficaz). Contudo, a hipótese da "graxa" estabelece que a corrupção pode conduzir a ganhos de eficiência num ambiente institucional ineficaz, ao contrário da hipótese da areia. A "natureza do custo" apresenta uma relação com a performance da firma, atribuindo sentidos diferentes. Se as instituições são eficientes e desenvolvidas a existência de corrupção na economia é baixa, logo não vai existir um efeito significativo. A literatura apresentada vem destacando a ausência de significância no efeito da corrupção nos ambientes institucionais desenvolvidos, uma vez que tais práticas são reflexo de ações marginais e não estruturais. Contudo, tal afirmativa não implica sua inexistência, visto que a corrupção marginal é consequência isolada de práticas pontuais e sujeita à presença do indivíduo, independentemente da sociedade que venha a se prevalecer (Lambsdorff, 2007).

2 Ver os trabalhos de Svensson (2005), Okada e Samreth (2012) e Hebous e Lipatov (2014). 


\section{Metodologia empírica}

\subsection{Definição da amostra e fonte dos dados}

Os dados usados na pesquisa foram extraídos do Enterprise Surveys, The World Bank. Esse relatório de desempenho empresarial abrange microdados em entrevistas com várias empresas em diversos países no mundo. Para um recorte exclusivo de entrevistas no Brasil, a amostra limitou-se ao tamanho de 3.444 empresas entrevistadas nos anos de 2003 e 2009.

As entrevistas foram distribuídas entre as 5 regiões e 15 unidades federativas ( $\mathrm{n}^{\circ}$ de firmas, \% no total): São Paulo (801, 23.26\%), Rio de Janeiro (288, 8.36\%), Minas Gerais (410, 11.90\%), Santa Catarina (352, 10.22\%), Rio Grande do Sul (387, 11.24\%), Paraná (343, 9.96\%), Distrito Federal (38, 1.10\%), Mato Grosso (93, 2.70\%), Ceará (182, 5.28\%), Pernambuco (45, 1.31\%), Maranhão (25, 0.73\%), Bahia (177, 5.14\%), Amazonas (78, $2.26 \%$ ), Goiás (164, 4.76\%) e Paraíba (61, 1.77\%).

A distribuição das empresas por setores consistiu em: alimentos, têxtil, vestuário, calçados e couro, químico, maquinários e equipamentos, autopeças, moveleiro, construção, serviços, atacado, varejo, hotéis e restaurantes, transporte e TI.

\subsection{Regressão quantílica com variáveis instrumentais}

O método aplicado neste trabalho segue os avanços propostos por Chernozhukov e Hansen (2008). A partir do método de Regressão Quantílica com Variáveis Instrumentais (RQ-VI), o modelo estimado consiste na seguinte equação estrutural:

$$
\begin{aligned}
& \ln \left(y_{i t}\right)=\beta_{0}+\beta_{1} \ln \left(L_{i t}^{S}\right)+\beta_{2} \ln \left(K_{i t}\right)+\beta_{3} \ln \left(L_{i t}^{S}\right) \cdot C_{i t}+\delta_{r}+\mu_{s}+\varepsilon_{i t} \\
& \ln \left(y_{i t}\right)=\beta_{0}+\beta_{1} \ln \left(L_{i t}^{S}\right)+\beta_{2} \ln \left(K_{i t}\right)+\beta_{3} \ln \left(K_{i t}\right) \cdot C_{i t}+\delta_{r}+\mu_{s}+\varepsilon_{i t} \\
& C_{i t}=\varphi\left(X, Z, \ln \left(\pi_{i t}\right)\right)+\vartheta_{i t}
\end{aligned}
$$

Conforme as equações estruturais M.1 e M.2, as variáveis $y, L_{S}, K, C$ correspondem, respectivamente, ao volume das vendas, ao estoque de mão 
de obra qualificada, aos investimentos em bens de capital e ao índice de percepção da corrupção. Com relação ao índice de percepção da corrupção, este foi normalizado no intervalo $[0,1]$, onde o extremo inferior $0=$ nenhuma percepção da corrupção (nenhum obstáculo) e 1= percepção máxima da corrupção (gravíssimo obstáculo).

As duas variáveis independentes no modelo principal representam proxies sobre duas importantes estratégias de investimentos da firma tratadas na literatura do crescimento endógeno em Acemoglu et al. (2006) e Aghion e Howitt (2009): (1) estratégias de imitação; e (2) estratégias de inovação. O primeiro componente é representado pela aquisição de bens de capital, cuja estratégia é relativamente mais estimuladora ao crescimento para as firmas mais afastadas da fronteira tecnológica. A segunda estratégia é capturada por importantes esforços em inovação, como os investimentos em P\&D. Contudo, o relatório do Enterprise Surveys não reporta informações sobre tais investimentos. Nesse sentido, Caselli e Coleman (2006) demonstraram que o padrão de tecnologia vigente em uma economia (ou setor ou firma) complementa um tipo específico de mão de obra. Conforme os autores, o estoque de capital humano apresenta composição entre alta e baixa qualificação. Ao desconsiderar essa composição, a teoria tradicional trata os fatores como substitutos perfeitos, o que não tem sido coerente com estudos posteriores, destacando Zhang e Zhuang (2011), Ang et al. (2011) e Basu e Mehra (2014). Nesse caso, a mão de obra com alta qualificação torna-se complementar com o padrão de tecnologia mais elevado. Na ausência de investimentos para sustentar esse padrão tecnológico, a mão de obra com alta qualificação se configura uma importante proxy. Na presente pesquisa, a distinção entre investimentos em bens de capital e estoque de mão de obra qualificada visa capturar a influência da corrupção na dinâmica da firma, por meio da composição das duas estratégias em direção à fronteira tecnológica.

A equação M.3 corresponde ao primeiro estágio da estimação, levando em consideração os fatores que afetam a percepção da corrupção, sendo que esta interage com os investimentos e com a demanda por mão de obra qualificada. Nesse primeiro estágio incluem-se os regressores exógenos $X=\left[\ln \left(L_{i} t^{S}\right), \ln \left(K_{i} t\right)\right]$ e os instrumentos excluídos $Z=\left[\ln \left(\pi_{i}\right), Z\right]$ que representam, respectivamente, os níveis dos lucros brutos $\left(\pi_{i t}\right)$ e um vetor de outras percepções que condicionam a corrupção $(Z)$, tais como: instabilidade política (inst_pol), atuação da administração fazendária (adm_trib), 
justiça (just) e os impostos (imp). Nesse caso, essas percepções foram obtidas a partir das respostas dos questionários, conforme diferentes graus de percepção de obstáculos à dinâmica dos negócios das firmas.

Quanto aos lucros, recentes estudos destacam o papel das métricas de desempenho das firmas como um incentivo à aplicação de investimentos específicos, como P\&D (Aghion; Howitt, 2009; Acemoglu et al., 2006). Entretanto, tais investimentos são sensivelmente susceptíveis a cenários de longo prazo, o que demanda por condições políticos estáveis e com baixa predominância de atividades predatórias.

Lambsdorff (2007) demonstra que os lucros se tornam um importante sinalizador para as práticas predatórias, uma vez que as práticas são incentivadas pela existência de recursos a serem apropriados. Assim, a existência de recursos potencialmente apropriados induz a um "preço" necessário para o devido andamento dos negócios, induzindo ao agente privado o efetivo "pagamento" para evitar mecanismos burocráticos excessivos. Contudo, os lucros apropriados pelos agentes privados infratores fortificam os "laços" construídos de forma ilícita com agentes públicos, demandando ainda mais recursos para proteger os negócios envolvidos. Nesse caso, os lucros consistem em um importante instrumento, uma vez que representam o "prêmio" pelas práticas ilícitas envolvidas. Sua ausência implicaria um sério erro de especificação ao modelo, comprometendo qualidades importantes nos parâmetros estimados e "viesando" o custo potencial da corrupção.

A Tabela 1 apresenta de forma resumida a definição de cada variável.

As quatro dimensões adicionais foram normalizadas no intervalo $[0,1]$, indicando o extremo inferior $0=$ nenhuma percepção de entrave aos negócios (nenhum obstáculo) e 1 = percepção máxima de entrave aos negócios (gravíssimo obstáculo).

Por último, os vetores $\delta_{r}, \mu_{s}$ capturam os efeitos fixos relativos às regiões e aos setores que afetam a dinâmica das vendas entre as firmas. As variáveis $\varepsilon, \vartheta$ representam todos os demais fatores não observados e que exercem a mínima influência no modelo estimado.

Visando garantir os critérios de eficiência ao modelo, as estimativas de erro-padrão dos parâmetros foram obtidas a partir da técnica de bootstrapping desenvolvida por Efron (1979), tomando o número de réplicas como igual a 400, conforme Andrews e Buchinsky (2001) na definição do tamanho equilibrado de réplicas ao modelo. 
Tabela 1 Descrição das variáveis do modelo

\begin{tabular}{|c|c|c|}
\hline Variável & $\begin{array}{l}\mathrm{N}^{\circ} \text { da } \\
\text { pergunta no } \\
\text { questionário }\end{array}$ & Descrição da variável no questionário \\
\hline C & J.30f & $\begin{array}{r}\text { "Fatores que afetam as operações atuais nos negócios" (Corrupção: } \\
\text { 0=Nenhum obstáculo, 1=Pequeno obstáculo, 2=Obstáculo moderado, } \\
\text { 3=Grande obstáculo, 4=Gravíssimo obstáculo) }\end{array}$ \\
\hline inst_pol & J.30e & $\begin{array}{r}\text { "Fatores que afetam as operações atuais nos negócios" (Instabilidade } \\
\text { Política: 0=Nenhum obstáculo, 1=Pequeno obstáculo, 2=0bstáculo } \\
\text { moderado, 3=Grande obstáculo, 4=Gravíssimo obstáculo) }\end{array}$ \\
\hline adm_trib & J.30b & $\begin{array}{l}\text { "Fatores que afetam as operações atuais nos negócios" (Atuação da } \\
\text { Administração Fazendária: } 0 \text { = Nenhum obstáculo, } 1 \text { = Pequeno obstáculo, } \\
2 \text { = Obstáculo moderado, } 3 \text { = Grande obstáculo, } 4 \text { = Gravíssimo obstáculo) }\end{array}$ \\
\hline just & H.30 & $\begin{array}{l}\text { "Fatores que afetam as operações atuais nos negócios" (Justiça: } \\
\begin{array}{r}0=\text { Nenhum obstáculo, } 1=\text { Pequeno obstáculo, } 2 \text { = Obstáculo moderado, } 3 \\
\text { = Grande obstáculo, } 4 \text { = Gravíssimo obstáculo) }\end{array}\end{array}$ \\
\hline imp & J.30a & $\begin{array}{l}\text { "Fatores que afetam as operações atuais nos negócios" (Impostos: } \\
\begin{array}{r}0=\text { Nenhum obstáculo, } 1=\text { Pequeno obstáculo, } 2 \text { = Obstáculo moderado, } 3 \\
\text { = Grande obstáculo, } 4 \text { = Gravíssimo obstáculo) }\end{array}\end{array}$ \\
\hline K & N.5a & $\begin{array}{l}\text { "No ano corrente, qual foi a despesa total na compra de bens de capital, } \\
\text { maquinários, veículos e equipamentos?" }\end{array}$ \\
\hline$L^{\mathrm{s}}$ & L.4a & $\begin{array}{l}\text { "No ano corrente, qual o número total de funcionários qualificados } \\
\text { permanentes e em tempo integral (Graduação e/ou mais)?" }\end{array}$ \\
\hline y & D.2 & "No ano corrente, qual foi o total das vendas da empresa?" \\
\hline- & \multicolumn{2}{|r|}{ Matriz de Custo ("No ano corrente, quais foram os custos totais por insumo") } \\
\hline CT1 & N.2a & "Mão de obra (incluindo ganhos, salários, bônus, pagamentos sociais etc.)" \\
\hline СT2 & N.2e & "Matérias-primas e bens intermediários usados na produção" \\
\hline СТ3 & N.2f & "Compra de combustível" \\
\hline CT4 & N.2b & "Eletricidade" \\
\hline CT5 & N.2c & "Serviços associados a telecomunicações" \\
\hline CT6 & N.2h & "Consumo de água" \\
\hline$\pi$ & - & "=D.2 $-($ Matriz de custos $=\mathrm{CT} 1+\mathrm{CT} 2+\mathrm{CT} 3+\mathrm{CT} 4+\mathrm{CT} 5+\mathrm{CT} 6) "$ \\
\hline
\end{tabular}

Fonte: Enterprise Surveys, The World Bank.

Usando os métodos de regressão quantílica e de regressão quantílica com variáveis instrumentais, foram empregados mínimos quadrados ordinários (MQO) e variáveis instrumentais, a fim de analisar os impactos sobre a média da distribuição e análise da validade e relevância dos instrumentos. Nos testes de validade e relevância dos instrumentos foram emprega- 
das as estatísticas J de Hansen e o multiplicador lagrangiano de Kleibergen e Paap (2006). A Tabela 2 apresenta um breve resumo nas hipóteses de cada estatística.

Tabela 2 Hipóteses das estatísticas de teste dos instrumentos

\begin{tabular}{l|r|r}
\hline \multirow{2}{*}{ Testes } & Hipótese nula & Resumo das estatísticas \\
\cline { 2 - 3 } & Instr. válidos e não correlacionados \\
J-Hansen & com o erro & Instr. inválidos e correlacionados \\
& com o erro \\
\hline $\begin{array}{l}\text { Kleibergen-Paap } \\
\text { (2006) }\end{array}$ & $\begin{array}{r}\text { Instr. redundantes e fracamente ou } \\
\text { não correlacionados com os regres- } \\
\text { sores endógenos }\end{array}$ & $\begin{array}{r}\text { Instr. relevantes e fortemente } \\
\text { correlacionados com os regressores } \\
\text { endógenos }\end{array}$ \\
\hline
\end{tabular}

Fonte: Elaboração própria.

As dimensões instabilidade política, atuação da receita federal (órgão da administração fazendária), justiça e os impostos foram usadas como instrumentos tanto em nível como na sua forma quadrática $\left(z+z^{2}\right)$. Esse procedimento visa capturar possíveis relações não lineares associadas às variáveis. Diante de quaisquer indícios de instrumentos impropriamente adicionados no primeiro estágio, o teste de Kleibergen e Paap (2006) sinaliza para uma possível não rejeição da hipótese nula, indicando que alguns instrumentos apresentam sinais de redundância estatística e, consequentemente, possível especificação incorreta do modelo no primeiro estágio.

Por fim, o efeito marginal dos investimentos e da mão de obra qualificada (elasticidade de cada insumo) depende do fator apropriação, cuja corrupção exerce sobre os fatores, reduzindo a sua eficácia sobre as vendas:

- Efeito marginal da corrupção na elastic. do capital:

$$
\epsilon_{K-y} \equiv \partial \ln \left(y_{i t}\right) / \partial \ln \left(K_{i t}\right)=\beta_{2}+\beta_{3} C
$$

- Efeito marginal da corrupção na elastic. do trabalho:

$$
\epsilon_{L-y} \equiv \partial \ln \left(y_{i t}\right) / \partial \ln \left(L_{i t}^{S}\right)=\beta_{2}+\beta_{3} C
$$




\section{Análise dos resultados}

\subsection{Análise descritiva dos dados}

A Tabela 3 apresenta a distribuição das empresas segundo o padrão de resposta na dimensão "percepção da corrupção". A região Norte apresentou menor percepção quanto à inexistência de obstáculos decorrentes da corrupção. Fato interessante ao se comparar com o outro extremo, de forma que a mesma região apresentou maior proporção nas respostas relativas a gravíssimo obstáculo. Embora se perceba diferença nas proporções entre as regiões, o teste de Pearson (qui-quadrado) não rejeita a hipótese nula de independência, ou seja, não aponta diferenças significativas na distribuição das respostas. Logo, a percepção da corrupção concentra-se em um gravíssimo obstáculo para o desenvolvimento dos negócios, sendo, portanto, um padrão estatisticamente homogêneo.

Tabela 3 Distribuição das respostas na dimensão da "corrupção como obstáculo para os negócios"

\begin{tabular}{|c|c|c|c|c|c|c|c|c|c|c|c|c|}
\hline \multirow{2}{*}{$\begin{array}{l}\text { Regiões } \\
\text { do Brasil }\end{array}$} & \multicolumn{2}{|c|}{$\begin{array}{r}\text { Nenhum } \\
\text { Obstáculo }\end{array}$} & \multicolumn{2}{|c|}{$\begin{array}{r}\text { Pequeno } \\
\text { Obstáculo }\end{array}$} & \multicolumn{2}{|c|}{$\begin{array}{l}\text { Obstáculo } \\
\text { moderado }\end{array}$} & \multicolumn{2}{|c|}{$\begin{array}{r}\text { Grande } \\
\text { obstáculo }\end{array}$} & \multicolumn{2}{|c|}{$\begin{array}{r}\text { Gravíssimo } \\
\text { obstáculo }\end{array}$} & \multicolumn{2}{|r|}{ Total } \\
\hline & F. Abs & F. Rel & F. Abs & F. Rel & F. Abs & F. Rel & F. Abs & F. Rel & F. Abs & F. Rel & F. Abs & F. Rel \\
\hline Centro Oeste & 32 & $11 \%$ & 18 & $6 \%$ & 37 & $13 \%$ & 83 & $28 \%$ & 124 & $42 \%$ & 294 & $100 \%$ \\
\hline Nordeste & 56 & $11 \%$ & 38 & $8 \%$ & 66 & $14 \%$ & 115 & $24 \%$ & 213 & $44 \%$ & 488 & $100 \%$ \\
\hline Norte & 6 & $8 \%$ & 5 & $7 \%$ & 7 & $9 \%$ & 18 & $24 \%$ & 40 & $53 \%$ & 76 & $100 \%$ \\
\hline Sudeste & 144 & $10 \%$ & 125 & $8 \%$ & 205 & $14 \%$ & 320 & $22 \%$ & 692 & $47 \%$ & 1486 & $100 \%$ \\
\hline Sul & 116 & $11 \%$ & 88 & $8 \%$ & 152 & $14 \%$ & 222 & $21 \%$ & 500 & $46 \%$ & 1078 & $100 \%$ \\
\hline Total & 354 & $10 \%$ & 274 & $8 \%$ & 467 & $14 \%$ & 758 & $22 \%$ & 1569 & $46 \%$ & 3422 & $100 \%$ \\
\hline
\end{tabular}

Teste de Pearson (Chi2) $=14.5580$

P-valor (Chi2) $=0.557$

Fonte: Elaboração própria, a partir dos resultados da pesquisa, 2003-2009.

Nota: A amostra total na tabela consistiu nas 3.444 empresas entrevistadas, menos 22 empresas que responderam "não saber" e/ou "não se aplica". As frequências relativas (F. Rel.) foram orientadas pelas linhas, capturando o valor relativo das respostas a cada região. 0 teste de Barlett não apresentou sinais de rejeição da hipótese nula de igualdade de variância entre os fatores.

Conforme se observa na Figura 1, a maior parte das empresas identificam que a corrupção consiste em um gravíssimo obstáculo para o desenvolvimento dos negócios (46\%). Levando em consideração que a corrupção 
consiste em algum nível de entrave para o desenvolvimento, 90\% identificam que essa falha institucional limita o dinamismo dos negócios.

Figura 1 Percepção da corrupção no Brasil, 2003-2009 - Corrupção como obstáculo ao desenvolvimento

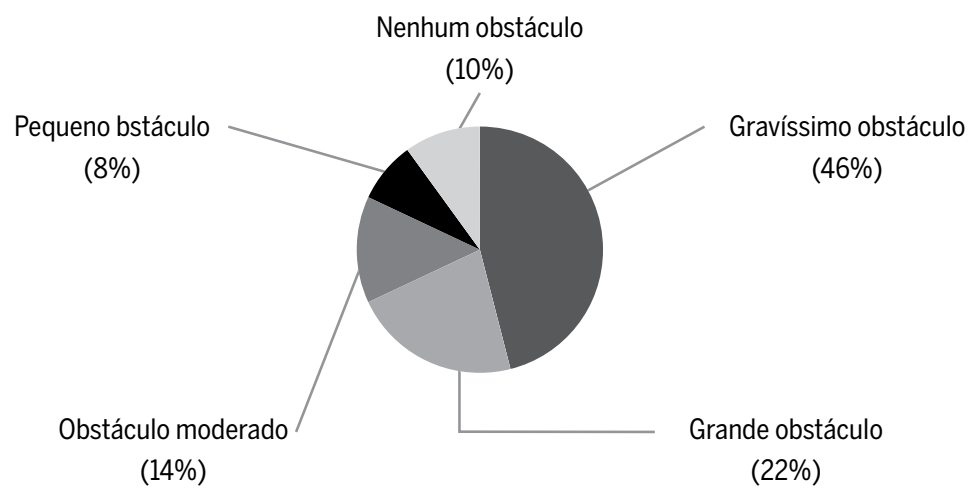

Fonte: Enterprise Surveys, The World Bank.

A Tabela 4 apresenta as principais estatísticas descritivas das variáveis empresariais, considerando a amostra total. Nota-se que as vendas e os investimentos em bens de capital apresentaram um declínio, comparando 2003 com 2009, um reflexo da crise mundial. As médias associadas às variáveis apresentaram um elevado coeficiente de variação, sugerindo fatores de concentração e tornando a média não representativa. Em 2003, 10\% das firmas apresentaram vendas de no máximo $\mathrm{R} \$ 224$ mil, bem abaixo do quantil superior de $90 \%$ com $\mathrm{R} \$ 33.800$ mil.

O estoque de mão de obra qualificada apresentou pouca variação entre os quantis nos anos analisados, com exceção dos quantis superiores, cuja variação apresentou ser mais perceptiva.

A seguir, são apresentados os resultados do modelo econométrico considerando a amostra total.

\subsection{Resultados dos modelos - regressões quantílicas}

Os primeiros resultados apresentam os efeitos da percepção da corrupção na redução da elasticidade dos investimentos em bens de capital, equação 


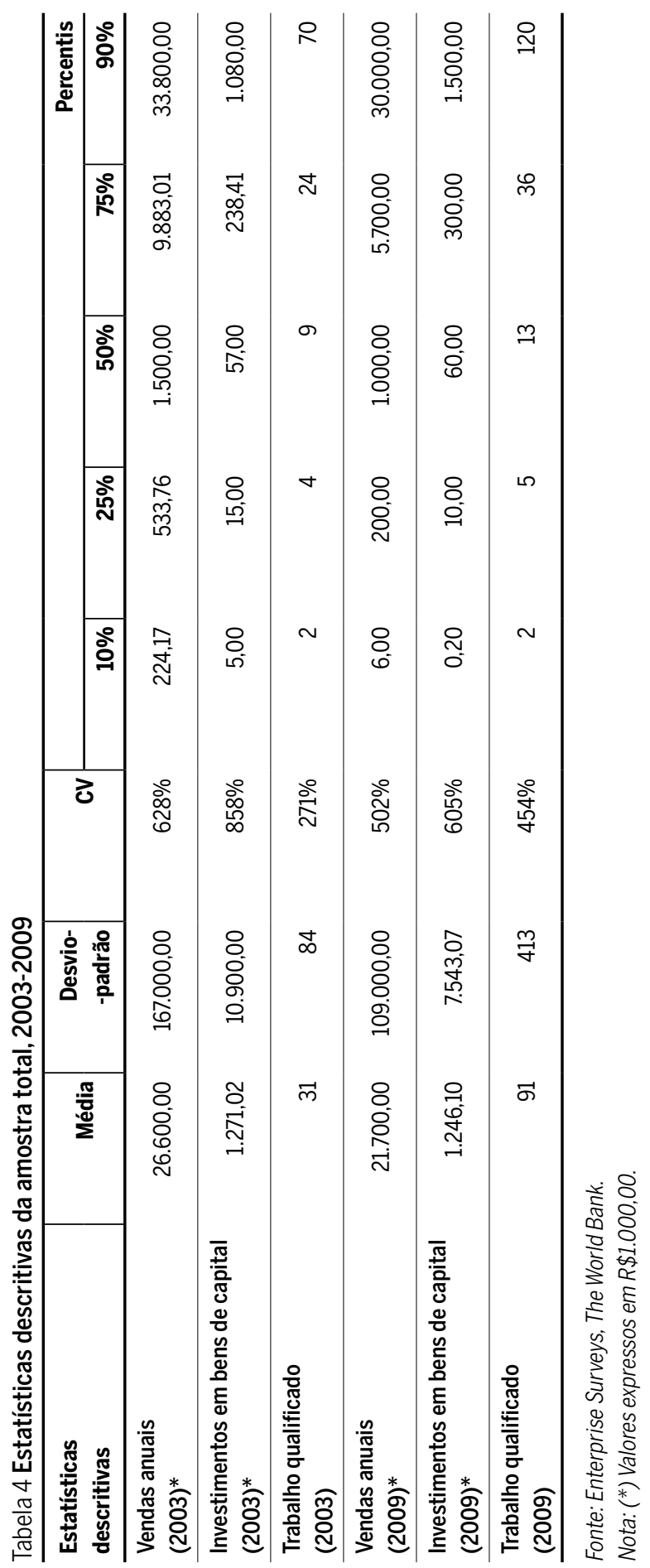


M.2 (Tabela 5). O método de $\mathrm{MQO}$ com efeitos fixos revela que os coeficientes de elasticidades entre os investimentos em bens de capital e mão de obra qualificada atendem os sinais esperados. Assim, 1\% de aumento nos investimentos em bens de capital pelas empresas que identificam a corrupção como nenhum obstáculo contribui, em média, para um crescimento nas vendas de $0,58 \%$. Já um aumento de $1 \%$ no estoque de mão de obra qualificada tende a aumentar as vendas em aproximadamente $0,31 \%$. Um importante destaque consiste nas diferenças entre as elasticidades no modelo MQO. A elasticidade parcial do capital tangível, para as firmas cuja percepção da corrupção consiste em nenhum obstáculo, é notoriamente maior em relação ao capital intangível (trabalho qualificado). Entretanto, esse padrão é revertido no método de regressão quantílica.

Tabela 5 Resultados do modelo M.2

\begin{tabular}{|c|c|c|c|c|c|c|}
\hline \multirow{2}{*}{ Variáveis } & \multirow{2}{*}{ MQO } & \multicolumn{5}{|c|}{ Regressão quantílica } \\
\hline & & $10 \%$ & $25 \%$ & $50 \%$ & $75 \%$ & $90 \%$ \\
\hline \multirow{2}{*}{$\log (K)$} & $* * * 0.587$ & $* * * 0.719$ & $* * * 0.716$ & $* * * 0.591$ & $* * * 0.539$ & $* * * 0.447$ \\
\hline & $(0.0193)$ & $(0.0343)$ & $(0.0257)$ & $(0.0216)$ & $(0.0250)$ & $(0.0312)$ \\
\hline \multirow{2}{*}{$\log \left(L^{s}\right)$} & $* * * 0.313$ & $* * * 0.150$ & $* * * 0.241$ & $* * * 0.346$ & $* * * 0.387$ & $* * * 0.420$ \\
\hline & $(0.0263)$ & $(0.0467)$ & $(0.0350)$ & $(0.0294)$ & $(0.0340)$ & $(0.0426)$ \\
\hline \multirow{2}{*}{$C^{*} \log (K)$} & $* * *-0.0311$ & -0.0233 & * -0.0223 & $* * *-0.0283$ & $* * *-0.0387$ & $* *-0.0318$ \\
\hline & $(0.00939)$ & $(0.0166)$ & $(0.0125)$ & $(0.0105)$ & $(0.0121)$ & $(0.0152)$ \\
\hline \multirow{2}{*}{ Constante } & $* * * 7.425$ & $* * * 5.597$ & $* * * 5.714$ & $* * * 7.241$ & $* * * 8.314$ & $* * * 9.464$ \\
\hline & $(0.689)$ & (1.220) & $(0.916)$ & $(0.768)$ & $(0.890)$ & $(1.112)$ \\
\hline Efeitos Fixos & - & - & - & - & - & - \\
\hline Setor & Sim & Sim & Sim & Sim & Sim & Sim \\
\hline Região & Sim & Sim & Sim & Sim & Sim & Sim \\
\hline [Pseudo-] $R^{2}$ & 0.590 & 0.362 & 0.353 & 0.398 & 0.410 & 0.400 \\
\hline
\end{tabular}

Fonte: Elaboração própria.

Nota: as estimativas de erro-padrão encontram-se entre os parêntesis. Os asteriscos representam a significância estatística conforme a legenda; ${ }^{* * *} p<0.01,{ }^{* *} p<0.05,{ }^{*} p<0.1$. As estimativas de erro-padrão foram obtidas a partir da técnica de bootstrap com 400 réplicas.

Ao longo dos quantis condicionais, o impacto dos investimentos tangíveis apresenta ser maior nos quantis inferiores. Isso sugere que as firmas com baixa performance usam o capital tangível com mais eficiência em comparação com o capital intangível. $\bigcirc$ aumento da elasticidade da mão de 
obra qualificada é acompanhado pelo aumento do quantil, indicando que as firmas com alto desempenho nas vendas apresentam maior coeficiente de elasticidade. O padrão inverso dos investimentos em bens de capital também pode ser vislumbrado. O impacto dos insumos varia à medida que diferenciamos empresas de baixa e alta performance, de forma que o tratamento sobre a média da distribuição torna-se impreciso para refletir tais diferenças. Além disso, nota-se pouco desvio dos parâmetros por quantil em relação à média $\mathrm{MQO}\left(C^{*} \log (K)\right)$, o que pode estar relacionado com a exclusão da endogeneidade observada na percepção da corrupção ver resultados seguintes na técnica de variáveis instrumentais.

Analisando o impacto da percepção da corrupção nos investimentos em bens de capital, os parâmetros estimados apresentaram sinais negativos em todos os quantis, sinalizando que a percepção da corrupção reduz o efeito marginal do investimento. A elasticidade final no $\tau$-quantil pode ser obtida a partir da derivada parcial: $\hat{\epsilon}_{\tau}^{k} \equiv \partial \ln \left(y_{i t}\right) / \partial \ln \left(K_{i t}\right)=\hat{\beta}_{2}-\hat{\beta}_{3} C$. A partir disso, quanto maior a percepção da corrupção, menor o coeficiente de elasticidade do investimento que é apropriado pelo custo da corrupção. Ao contrário do método $\mathrm{MQO}$, o custo da corrupção varia conforme o quantil condicional, refletindo que empresas com diferentes performances apresentam pesos diferentes no custo da corrupção. Analisando o custo da corrupção para as empresas que percebem como um gravíssimo obstáculo, a elasticidade dos bens de capital é representada na Figura 2 .

Figura 2 Elasticidade dos investimentos em bens de capital após "efeito" da corrupção

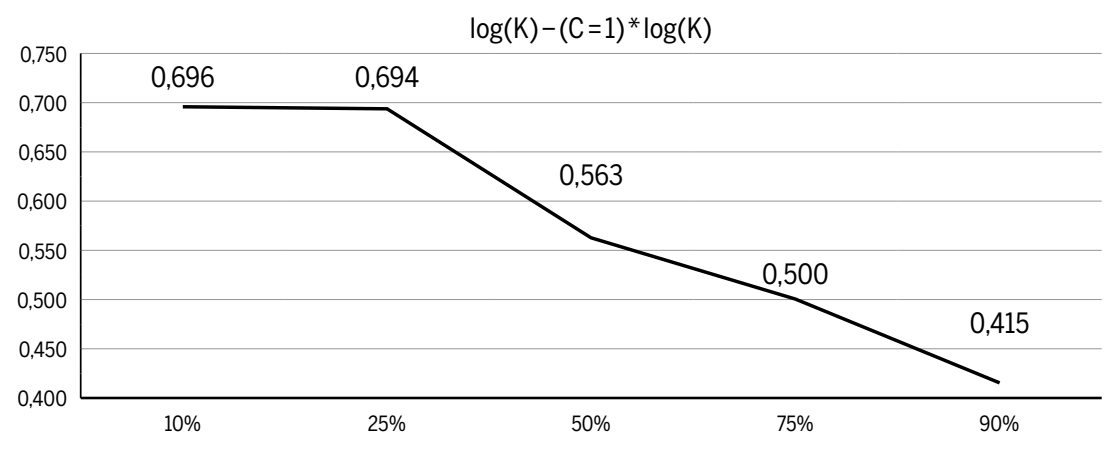

Fonte: Elaboração própria.

No modelo MQO o custo médio da corrupção para as empresas com gravíssima percepção consiste em $0,03 \%$ na redução da elasticidade média 
$(0,313-0,0311=0,282 \%)$. Assim, comparando os extremos da percepção, as empresas que não identificam a corrupção como um obstáculo apresentam uma elasticidade de $0,313 \%$, o que representa aumento de $11 \%$ em relação às empresas com gravíssima percepção.

Controlando o modelo a partir da técnica de regressão quantílica, as elasticidades finais se alteraram apresentando evolução decrescente com o aumento dos quantis condicionais. Para as empresas que identificam a corrução como um gravíssimo obstáculo, o coeficiente de elasticidade nos quantis inferiores $(10 \%$ ) corresponde a $68 \%$ acima do limite superior (quantil 90\%). Essa diferença entre as elasticidades vai declinando para $67 \%$ (quantil 25\%), 36\% (quantil 50\%) e 20\% (quantil $75 \%$ ). Esse padrão sugere que o custo da corrupção tende a apresentar maior peso nas firmas com maior performance, ou situadas nos quantis superiores.

A Tabela 6 apresenta os resultados a partir da influência da corrupção no estoque de mão de obra qualificada das empresas. Novamente, o coeficiente de elasticidade parcial dos investimentos em bens de capital foi maior que o da mão de obra qualificada (MOO) - parâmetros significativos a $1 \%$. O efeito interativo da percepção da corrupção no estoque de mão de obra qualificada apresentou sinal negativo, de forma que a elasticidade desse fator para as empresas que identificam a corrupção como um gravíssimo obstáculo ao desenvolvimento apresentou o valor de $0,273 \%$, bem abaixo das empresas que não identificam a corrupção como um gravíssimo obstáculo (0,375\%). Isso equivale a uma variação de $37 \%$ acima das empresas cuja percepção verificou-se em gravíssimo entrave para o desenvolvimento dos negócios locais.

Avaliando os resultados da regressão quantílica, percebe-se clara inversão entre os parâmetros quando aumentamos os quantis condicionais. $\mathrm{Na}$ parte inicial da distribuição, a elasticidade do capital é maior que a elasticidade da mão de obra. Isso sugere que as firmas com baixa performance nas vendas obtêm maior retorno com os investimentos em bens de capital, em comparação com o trabalho qualificado. Essa relação é gradativamente invertida à medida que os quantis condicionais vão aumentando, de forma que nas firmas com alta performance, o uso do trabalho qualificado passa a ser estrategicamente superior em relação ao capital físico da empresa parâmetros significativos a $1 \%$. 
Tabela 6 Resultados do modelo M.1

\begin{tabular}{|c|c|c|c|c|c|c|}
\hline \multirow{2}{*}{ Variáveis } & \multirow{2}{*}{ MQO } & \multicolumn{5}{|c|}{ Regressão quantílica } \\
\hline & & $10 \%$ & $25 \%$ & $50 \%$ & $75 \%$ & $90 \%$ \\
\hline \multirow{2}{*}{$\log (K)$} & $* * * 0.589$ & $* * * 0.727$ & $* * * 0.711$ & $* * * 0.612$ & $* * * 0.537$ & $* * * 0.447$ \\
\hline & $(0.0181)$ & $(0.0337)$ & $(0.0232)$ & $(0.0201)$ & $(0.0211)$ & $(0.0319)$ \\
\hline \multirow{2}{*}{$\log \left(L^{S}\right)$} & $* * * 0.375$ & $* * * 0.180$ & $* * * 0.236$ & $* * * 0.375$ & $* * * 0.487$ & $* * * 0.537$ \\
\hline & $(0.0351)$ & $(0.0653)$ & $(0.0449)$ & $(0.0388)$ & $(0.0408)$ & $(0.0618)$ \\
\hline \multirow{2}{*}{$C^{*} \log \left(L^{S}\right)$} & $* * *-0.102$ & * -0.110 & -0.00882 & $*-0.0658$ & $* * * * 0.162$ & $* * *-0.189$ \\
\hline & $(0.0345)$ & $(0.0641)$ & $(0.0441)$ & $(0.0381)$ & $(0.0400)$ & $(0.0606)$ \\
\hline \multirow{2}{*}{ Constante } & $* * * 7.471$ & $* * * 4.659$ & $* * * 5.360$ & $* * * 7.103$ & $* * * 8.806$ & $* * * 10.55$ \\
\hline & $(0.200)$ & $(0.371)$ & (0.255) & $(0.221)$ & $(0.232)$ & $(0.351)$ \\
\hline Efeitos Fixos & - & - & - & - & - & - \\
\hline Setor & Sim & Sim & Sim & Sim & Sim & Sim \\
\hline Região & Sim & Sim & Sim & Sim & Sim & Sim \\
\hline [Pseudo-] $\mathrm{R}^{2}$ & 0.568 & 0.343 & 0.339 & 0.380 & 0.389 & 0.366 \\
\hline
\end{tabular}

Fonte: Elaboração própria.

Nota: as estimativas de erro-padrão encontram-se entre os parêntesis. Os asteriscos representam a significância estatística conforme a legenda; ${ }^{* *} p<0.01$, ${ }^{* *} p<0.05,{ }^{*} p<0.1$. As estimativas de erro-padrão foram obtidas a partir da técnica de bootstrap com 400 réplicas.

Analisando o efeito interativo da corrupção no estoque de mão de obra qualificada, o coeficiente estimado apresentou sinal negativo em todos os quantis condicionais - somente o quantil $25 \%$ não apresentou significância estatística. Além disso, o efeito apresentou um padrão de declínio entre os quantis $10 \%-50 \%$, e crescente nos quantis seguintes $75 \%-90 \%$. O efeito final da elasticidade do trabalho qualificado para as firmas com percepção de gravíssimo obstáculo é representado na Figura 3. Embora o efeito interativo da percepção da corrupção no estoque de mão de obra qualificada tenha se apresentado declinante nos quantis condicionais, o resultado final da elasticidade nas firmas que identificam a corrupção como gravíssimo obstáculo apresentou um padrão crescente. Essa observação mostra que a percepção da corrupção tende a apresentar custos superiores para as firmas com baixa performance. Nesse sentido, as firmas nos quantis superiores (90\%) apresentaram variação superior a quatro vezes em relação ao quantil inferior (10\%). Uma diferença que declina à medida que se aumentam os quantis: $53 \%$ (quantil 25\%), 13\% (quantil 50\%) e 7\% (quantil $75 \%$ ). 
Figura 3 Elasticidade do trabalho qualificado após "efeito" da corrupção

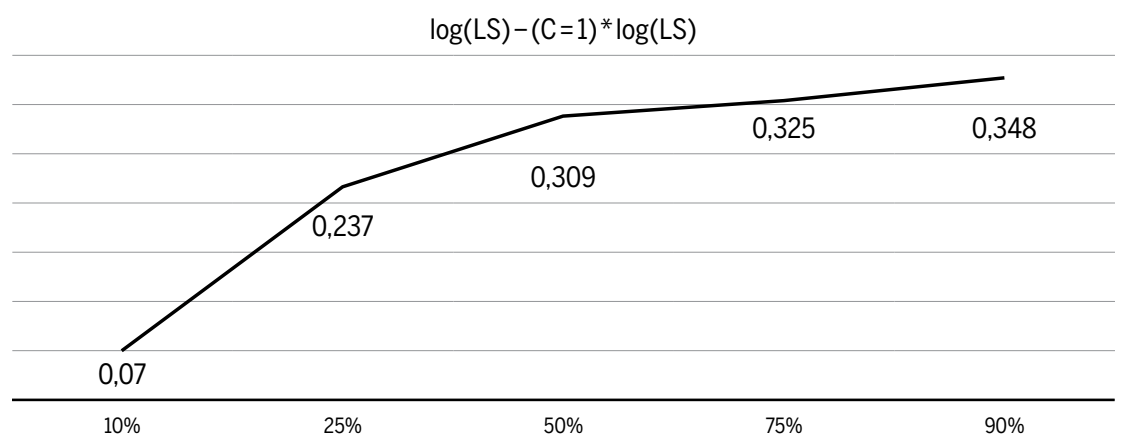

Fonte: Elaboração própria.

\subsection{Resultados dos modelos - Regressões quantílicas com variáveis instrumentais}

Nesta seção são apresentadas as estimativas do modelo anterior a partir da técnica de regressão quantílica com variáveis instrumentais. Conforme os resultados da Tabela 7, as estimativas de variáveis instrumentais (VI) apresentaram significância estatística em todas as variáveis ( $1^{a}$ coluna). $O$ efeito interativo da percepção da corrupção com o estoque de trabalho qualificado apresentou sinal negativo, conforme anteriormente apresentado. Contudo, o viés entre as estimativas VI e MQO (Tabela 6) demonstrou ser superior, em sua magnitude, para a primeira em relação à segunda no equivalente a $40 \%(|0,142|$ contra $|0,102|)$. Outras diferenças também são perceptíveis nos demais parâmetros, destaque nas elasticidades do capital com $15 \%(0,676$ em VI contra 0,589 em MOO) e parcial do trabalho qualificado $(0,396 \mathrm{em} \mathrm{VI}$ contra $0,375 \mathrm{em} \mathrm{MQO})$. Os testes de validade dos instrumentos corroboraram a devida exclusão. $\bigcirc$ teste J de Hansen não rejeitou a hipótese nula de instrumentos válidos e não correlacionados com a perturbação estocástica. Em seguida, a estatística de Kleibergen e Paap demonstrou rejeitar a hipótese nula de instrumentos redundantes e fracamente correlacionados com os regressores endógenos. A partir desses resultados, as percepções associadas a justiça, atuação da administração fazendária, impostos e instabilidade política, além dos lucros brutos das firmas, ajudam a definir uma melhor compreensão da corrupção, cujo controle repercute em um custo notoriamente superior ao da "falha institucional" no desempenho das vendas. 
Tabela 7 Resultados do modelo M.1 - RQVI

\begin{tabular}{|c|c|c|c|c|c|c|}
\hline \multirow{2}{*}{ Variáveis } & \multirow{2}{*}{ VI } & \multicolumn{5}{|c|}{ Regressão quantílica com variáveis instrumentais (RQVI) } \\
\hline & & $10 \%$ & $25 \%$ & $50 \%$ & $75 \%$ & $90 \%$ \\
\hline$C^{*} \log \left(L^{S}\right)$ & $\begin{array}{l}*-0.142 \\
(0.0834)\end{array}$ & $\begin{array}{r}0.0115 \\
(0.129)\end{array}$ & $\begin{array}{r}-0.0405 \\
(0.101)\end{array}$ & $\begin{array}{l}-0.0381 \\
(0.0918)\end{array}$ & $\begin{array}{r}* * *-0.348 \\
(0.101)\end{array}$ & $\begin{array}{r}* * *-0.374 \\
(0.130)\end{array}$ \\
\hline $\log (K)$ & $\begin{array}{l}* * * 0.676 \\
(0.0350)\end{array}$ & $\begin{array}{l}* * * 0.762 \\
(0.0309)\end{array}$ & $\begin{array}{l}* * * 0.727 \\
(0.0242)\end{array}$ & $\begin{array}{l}* * * 0.629 \\
(0.0220)\end{array}$ & $\begin{array}{r}* * * 0.563 \\
(0.0243)\end{array}$ & $\begin{array}{r}* * * 0.495 \\
(0.0312)\end{array}$ \\
\hline $\log \left(L^{S}\right)$ & $\begin{array}{r}* * * 0.396 \\
(0.0702)\end{array}$ & $\begin{array}{r}0.141 \\
(0.0973)\end{array}$ & $\begin{array}{r}* * * 0.263 \\
(0.0762)\end{array}$ & $\begin{array}{r}* * * 0.338 \\
(0.0692)\end{array}$ & $\begin{array}{l}* * * 0.627 \\
(0.0764)\end{array}$ & $\begin{array}{r}* * * 0.654 \\
(0.0982)\end{array}$ \\
\hline Constante & $\begin{array}{r}* * * 5.002 \\
(0.533)\end{array}$ & $\begin{array}{r}* * * 2.928 \\
(0.377)\end{array}$ & $\begin{array}{r}* * * 4.175 \\
(0.295)\end{array}$ & $\begin{array}{r}* * * 6.182 \\
(0.268)\end{array}$ & $\begin{array}{r}* * * 7.822 \\
(0.296)\end{array}$ & $\begin{array}{r}* * * 9.915 \\
(0.380)\end{array}$ \\
\hline Efeitos Fixos & - & - & - & - & - & - \\
\hline Setor & Sim & Sim & Sim & Sim & Sim & Sim \\
\hline Região & Sim & Sim & Sim & Sim & Sim & Sim \\
\hline Hansen J statistic & 1.802 & - & - & - & - & - \\
\hline $\mathrm{p}$-value of Hansen $\mathrm{J}$ & 0.772 & - & - & - & - & - \\
\hline $\begin{array}{l}\text { Kleibergen-Paap } \\
\text { LM test statistic }\end{array}$ & 170.7 & - & - & - & - & - \\
\hline $\begin{array}{l}\text { p-value of Kleiber- } \\
\text { gen-Paap test }\end{array}$ & 0.0000 & - & - & - & - & - \\
\hline
\end{tabular}

Fonte: Elaboração própria.

Nota: as estimativas de erro-padrão encontram-se entre os parêntesis. Os asteriscos representam a significância estatística conforme a legenda; ${ }^{* *} p<0.01,{ }^{* *} p<0.05,{ }^{*} p<0.1$. As estimativas de erro-padrão foram obtidas a partir da técnica de bootstrap com 400 réplicas.

As elasticidades dos investimentos em bens de capital apresentam declínio com o aumento dos quantis, sugerindo, como na análise anterior, que as firmas com baixa performance exploram melhor os resultados nas vendas a partir dos investimentos aplicados. Confrontando os resultados da regressão quantílica com variáveis instrumentais e o estimador tradicional, o viés capturado pela diferença entre as estimativas revelou que o método de VI ao longo dos quantis apresenta resultados com magnitudes superiores. Essa diferença pode ser observada em uma variação superior de $5 \%$ no quantil $10 \%, 2 \%$ no quantil $25 \%, 3 \%$ no quantil $50 \%, 5 \%$ no quantil $75 \%$ e $11 \%$ no quantil $90 \%$. Isso revela que a ausência do controle nos aspectos institucionais da corrupção subestima o impacto dos investimentos em bens de capital no estimador tradicional de Koenker e Bassett (1978). 
As diferenças entre os coeficientes de elasticidade também podem ser vistas no trabalho qualificado (considerando as firmas que identificam a corrupção como nenhum obstáculo), expostos na Figura 4. Nos quantis $10 \%$ e $50 \%$, as estimativas por VI apresentaram ser inferiores à proporção de $22 \%$ e $10 \%$, respectivamente. Nos demais quantis, as diferenças apontam para uma subestimação no estimador de Koenker e Bassett, de forma que as estimativas de VI apresentam magnitudes superiores na proporção de $11 \%$ no quantil $25 \%$, $29 \%$ no quantil $75 \%$ e $22 \%$ no quantil $90 \%$. Considerando a interação entre a percepção da corrupção e o estoque de trabalho qualificado, o método por variáveis instrumentais apresentou parâmetros superiores nos quantis $25 \%, 75 \%$ e $90 \%$ em relação ao método tradicional. No que tange à elasticidade final, incluindo o efeito da percepção da corrupção nas firmas que identificam como gravíssimo obstáculo, a elasticidade do trabalho qualificado apresenta um padrão crescente, seguindo a mesma interpretação dos resultados anteriores.

Figura 4 Elasticidade do trabalho qualificado após "efeito" da corrupção, RQVI.

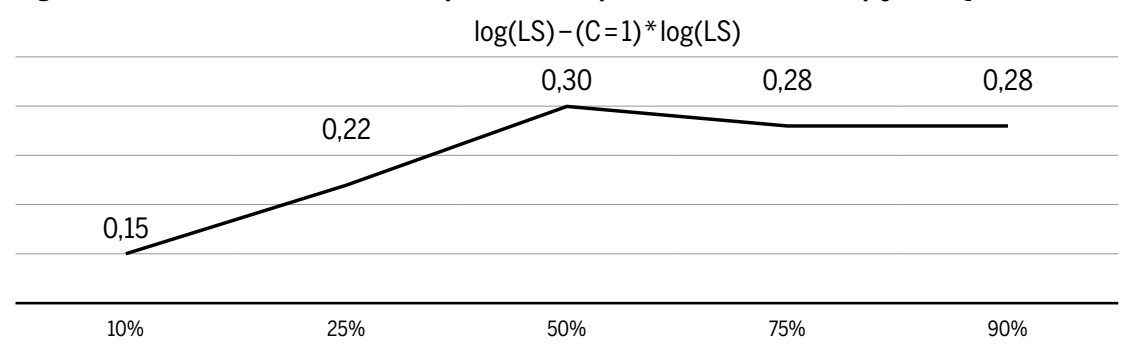

Fonte: Elaboração própria.

Incluindo o custo da percepção da corrupção nos casos de gravíssimo obstáculo, a elasticidade final apresenta um padrão crescente nos quantis, de forma que as empresas com baixa performance nas vendas, descontado o efeito perceptivo da corrupção, são menos eficientes no uso do trabalho qualificado. Esse padrão, também observado nas tabelas anteriores, sinaliza que o custo final da corrupção a partir da elasticidade descontada do efeito retrativo da percepção recai de maneira superior nas firmas situadas nos quantis inferiores.

A Tabela 8 apresenta os resultados da regressão quantílica com variáveis instrumentais considerando o efeito da corrupção nos investimentos em bens de capital. A técnica de variáveis instrumentais gerou uma esti- 
mativa da elasticidade do capital positiva e aproximadamente $20 \%$ acima do método de MQO. Com relação à estimativa da elasticidade da mão de obra qualificada, o resultado por VI foi positivo e com uma magnitude inferior em torno de $4 \%$ em relação ao MQO.

Tabela 8 Resultados do modelo M.2 - RQVI

\begin{tabular}{|c|c|c|c|c|c|c|}
\hline \multirow{2}{*}{ Variáveis } & \multirow{2}{*}{ VI } & \multicolumn{5}{|c|}{ Regressão quantílica com variáveis instrumentais (RQVI) } \\
\hline & & $10 \%$ & $25 \%$ & $50 \%$ & $75 \%$ & $90 \%$ \\
\hline$C^{*} \log (K)$ & $\begin{array}{l}{ }^{*}-0.0370 \\
(0.0226)\end{array}$ & $\begin{array}{r}* * *-0.163 \\
(0.0348)\end{array}$ & $\begin{array}{r}* * * 0.0850 \\
(0.0235)\end{array}$ & $\begin{array}{r}* * * 0.212 \\
(0.0268)\end{array}$ & $\begin{array}{r}* * *-0.228 \\
(0.0306)\end{array}$ & $\begin{array}{r}* * * 0.165 \\
(0.0371)\end{array}$ \\
\hline $\log (\mathrm{K})$ & $\begin{array}{l}* * * 0.699 \\
(0.0405)\end{array}$ & $\begin{array}{r}* * * 0.228 \\
(0.0485)\end{array}$ & $\begin{array}{l}* * * 0.210 \\
(0.0328)\end{array}$ & $\begin{array}{l}* * * 0.311 \\
(0.0374)\end{array}$ & $\begin{array}{r}* * * 0.332 \\
(0.0427)\end{array}$ & $\begin{array}{r}0.0828 \\
(0.0516)\end{array}$ \\
\hline $\log \left(L^{s}\right)$ & $\begin{array}{l}* * * 0.300 \\
(0.0495)\end{array}$ & $\begin{array}{r}0.0178 \\
(0.0613)\end{array}$ & $\begin{array}{l}{ }^{* *} 0.106 \\
(0.0414)\end{array}$ & $\begin{array}{l}* * * 0.176 \\
(0.0472)\end{array}$ & $\begin{array}{l}* * * 0.208 \\
(0.0539)\end{array}$ & $\begin{array}{r}* * * 0.305 \\
(0.0653)\end{array}$ \\
\hline Constante & $\begin{array}{r}* * * 5.043 \\
(0.530)\end{array}$ & $\begin{array}{r}1.660 \\
(1.253)\end{array}$ & $\begin{array}{r}* * 2.637 \\
(0.846)\end{array}$ & $\begin{array}{r}* * 2.526 \\
(0.965)\end{array}$ & $\begin{array}{r}* * * 8.048 \\
(1.102)\end{array}$ & $\begin{array}{r}* * * 13.03 \\
(1.334)\end{array}$ \\
\hline Efeitos Fixos & - & - & - & - & - & - \\
\hline Setor & Sim & Sim & Sim & Sim & Sim & Sim \\
\hline Região & Sim & Sim & Sim & Sim & Sim & Sim \\
\hline Hansen J statistic & 1.942 & - & - & - & - & - \\
\hline $\mathrm{p}$-value of Hansen $\mathrm{J}$ & 0.746 & - & - & - & - & - \\
\hline $\begin{array}{l}\text { Kleibergen-Paap } \\
\text { LM test statistic }\end{array}$ & 197.1 & - & - & - & - & - \\
\hline $\begin{array}{l}\text { p-value of Kleiber- } \\
\text { gen-Paap test }\end{array}$ & 0.0000 & - & - & - & - & - \\
\hline
\end{tabular}

Fonte: Elaboração própria.

Nota: as estimativas de erro-padrão encontram-se entre os parêntesis. Os asteriscos representam a significância estatística conforme a legenda; ${ }^{* *} p<0.01$, ${ }^{* *} p<0.05,{ }^{*} p<0.1$. As estimativas de erro-padrão foram obtidas a partir da técnica de bootstrap com 400 réplicas.

Com relação ao efeito cruzado entre a percepção da corrupção e o investimento em bens de capital, o parâmetro obtido por VI apresentou sinal negativo e com magnitude superior em relação ao alternativo MQO de aproximadamente $20 \%$. Essa diferença expressiva entre as estimativas aponta para um viés no resultado a partir da técnica de $\mathrm{MQO}$, assim como nos resultados da tabela anterior, assinalando para um custo subestimado da corrupção associado ao erro de medição. Nesse sentido, o controle da percepção, 
a partir de outras dimensões institucionais relevantes, ajusta o impacto da corrupção para um custo notoriamente maior nas vendas das firmas.

Novamente, as estatísticas de validade dos instrumentos parecem satisfazer os critérios desejados. $O$ teste J de Hansen aponta para uma não rejeição da hipótese nula, de forma que os instrumentos não apresentam correlação com a perturbação estocástica. Da mesma maneira, a estatística de Kleibergen e Paap rejeita a hipótese nula de instrumentos redundantes no nível de $1 \%$ de significância.

A evolução das elasticidades ao longo dos quantis mostra o mesmo padrão observado anteriormente: elasticidade decrescente dos investimentos em bens de capital para as firmas de alta performance e o crescimento a partir da utilização da mão de obra qualificada. Considerando ambas as variáveis, as estimativas de regressão quantílica por VI apresentaram resultados com magnitudes inferiores aos resultados obtidos pelo estimador de Koenker e Bassett. Tal fato sugere que a inclusão da corrupção no efeito cruzado sob os investimentos em bens de capital superestima as elasticidades uma vez que os aspectos associados à percepção institucional, a partir de novos fatores, deixam de capturar uma compreensão mais precisa da percepção da corrupção.

A Figura 5 apresenta um padrão inverso do coeficiente de elasticidade dos investimentos em bens de capital após o desconto da percepção da corrupção nas firmas que identificam como gravíssimo obstáculo. Percebe-se o crescimento da elasticidade à medida que se aumentam os quantis condicionais. Essa inversão de resultado revela que nas firmas com baixa performance nas vendas, embora apresentem um efeito médio acima das firmas situadas nos quantis superiores, o desconto da percepção da corrupção torna o efeito final da elasticidade inferior em relação às firmas com alta performance.

Dessa forma, o controle da percepção da corrupção pelos instrumentos selecionados inverte a elasticidade do investimento, direcionando o efeito final para uma maior penalização sobre as firmas com baixa performance. Esse mesmo padrão é identificado na elasticidade da mão de obra qualificada. Os resultados indicam que a "falha institucional" direciona para uma assimetria na distribuição das vendas das empresas, favorecendo as firmas de baixo desempenho e "favorecendo", relativamente, as firmas de alto desempenho. 
Figura 5 Elasticidade dos investimentos em bens de capital qualificado após "efeito" da corrupção, RQVI

\begin{tabular}{c}
\multicolumn{4}{c}{$\log (\mathrm{K})-(\mathrm{C}-1)+\log (\mathrm{K})-\mathrm{RQVI}$} \\
\hline
\end{tabular}

Fonte: Elaboração própria.

\subsection{Discussão com as pesquisas recentes}

Na realidade brasileira, Nishijima et al. (2017), estudando o setor de saúde básica em municípios brasileiros, identificaram que procedimentos de gestão, especificamente a descentralização administrativa, reduz significativamente a corrupção. Por outro lado, Carraro et al. (2016) apontaram que tanto o empreendedorismo quanto o mercado de trabalho informal e o tamanho das firmas são afetados pela presença da corrupção nas unidades federativas brasileiras. Em outra análise, Melo, et al. (2015) encontraram evidências significativas da corrupção no grau de abertura das empresas. Contudo a técnica empregada no estudo em questão consistiu na análise de regressão com dados em painel entre 2000-2008, e os possíveis efeitos de endogeneidade não foram adequadamente trabalhados, o que pode justificar resultados com padrões distintos.

Estudos de Bologna e Ross (2015), em nível municipal no Brasil, concluíram que a corrupção impactou negativamente no número de estabelecimentos industriais ao longo dos anos 2003-2012, independentemente do tamanho dos estabelecimentos. Estratificando a amostra por setor industrial, num total de 17 setores, 12 são afetados negativamente pela corrupção. Embora as conclusões apontem para a presença de um "efeito graxa na engrenagem", tal efeito não é dominante no tempo, consequentemente, a corrupção impede o crescimento da atividade empresarial.

Conforme Hebous e Lipatov (2014), empresas que atuam em países com elevados índices de corrupção tendem a transferir suas rendas para 
os "paraísos fiscais", com o intuito de se protegerem dos efeitos nocivos da expropriação, chantagens e da instabilidade política em que tais economias estão mais propensas a atuar. Nesse sentido, o investimento das empresas nos países corruptos tende a se reduzir com a volatilidade das taxas de juros e com o fluxo de "propina" paga aos oficiais públicos. Embora os "governos corruptos" tendam a se beneficiar com as altas taxas aplicadas, em decorrência da instabilidade da política econômica, esse efeito é compensado negativamente pela redução direta dos investimentos e da transferência do capital.

Em longo prazo, percebe-se a transferência de bem-estar entre as economias, com a redução do consumo e do investimento privado nos países corruptos para as economias que melhor protegem a propriedade privada (Svensson, 2005).

Embora esses estudos tenham sinalizado para os efeitos restritivos da corrupção em longo prazo, poucas abordagens têm destacado esses efeitos em diferentes partes da distribuição condicional. Okada e Samreth (2012) analisaram o impacto da ajuda externa na redução dos níveis corrupção dos países. Adotando o estimador de Koenker e Bassett de regressão quantílica, os resultados mostraram que, nos países com baixos índices de corrupção, o impacto da ajuda externa tende a ser maior na redução da corrupção. Embora o desenvolvimento econômico contribua para a redução da corrupção em todos os níveis quantílicos, a magnitude do impacto diminui com o nível de corrupção, que é refletido pela queda acentuada dos parâmetros ao longo dos quantis condicionais. Além disso, a democracia reduz significativamente a corrupção nos países mais propensos, sugerindo que o impacto de redução aumenta com o nível de corrupção (Okada; Samreth, 2012).

Outros estudos apontam para o efeito da corrupção em diferentes contextos das firmas. Wang e You (2012) mostraram que em ambientes mais competitivos, com a predominância de menor concentração, as firmas privadas encontram-se mais propensas a cometerem suborno, objetivando maiores lucros por meio de informações privilegiadas de mercado junto aos oficiais públicos.

Distinguindo as firmas conforme o porte, Jiang e Nie (2014) identificaram que as firmas de pequeno porte tendem a apresentar maior impacto da percepção da corrupção nos seus resultados operacionais, em comparação àquelas de médio e grande porte. As firmas "menores" são mais limitadas 
operacionalmente para lidar com os custos irrecuperáveis da corrupção, e firmas maiores têm maior poder de barganha, o que as torna menos vulneráveis ao risco inerente das atividades predatórias. Esses resultados são coerentes com o comportamento da corrupção nas firmas do Brasil. Em diferentes níveis de desenvolvimento regional, firmas com maior performance e mais propensas nas regiões mais desenvolvidas parecem ser menos desfavorecidas, embora a percepção da corrupção se apresente de forma homogênea entre as regiões. Isso sugere, em termos médios, que nas regiões menos desenvolvidas e com maior participação, de firmas com menor performance, os custos da corrupção são maiores no desenvolvimento dos seus negócios.

Esses resultados são coerentes com as recentes pesquisas, sugerindo que a assimetria observada entre as firmas e as regiões apresenta dinâmicas diferentes com a presença da corrupção. Nesse caso, o custo da corrupção na dinâmica dos negócios é maior na baixa performance (quantis inferiores) em relação à alta performance (quantis superiores).

Sobre o padrão crescente nas elasticidades parciais da mão de obra qualificada (e decrescentes nos investimentos em bens de capital), os resultados apresentados corroboram os recentes estudos da literatura do crescimento endógeno. Os trabalhos de Acemoglu et al. (2006), Ang et al. (2011), Rocha, Dal-Poz e Silveira (2013) e Basu e Mehra (2014) apontam que o recurso humano qualificado tem maior impacto no crescimento, especialmente nas economias mais próximas da fronteira tecnológica.

Coad (2011) empregou o conceito de distância da fronteira usando a técnica de regressão quantílica. Os resultados do estudo mostram que os recursos destinados à inovação, compreendendo os investimentos diretos à contratação de mão de obra qualificada, têm maior impacto na geração de valor nos quantis superiores ou nas firmas mais próximas da fronteira. Isso indica, no presente estudo, que as firmas com elevada performance empregam o trabalho qualificado com maior eficiência em relação àquelas situadas nos quantis inferiores (baixa performance).

\section{Considerações finais}

O presente estudo analisou o impacto da percepção da corrupção nas vendas das firmas no Brasil, conforme diferentes desempenhos. A percepção 
da corrupção revelou-se estatisticamente homogênea entre os estados e as regiões. Aproximadamente metade das firmas identifica a corrupção como gravíssimo obstáculo para o desenvolvimento dos seus negócios e quase 90\% identificam que a corrupção exerce alguma influência nos negócios, desde o pequeno ao gravíssimo obstáculo.

Comparando o estimador de Koenker e Bassett com o de Chernozhukov e Hansen, as estimativas apresentaram divergência considerável, atribuindo erros de medição no impacto da corrupção. Os primeiros resultados sugerem maior impacto nas firmas situadas nos quantis superiores. Atribuindo o valor da corrupção como gravíssimo obstáculo, o coeficiente de elasticidade final apresentou tendência crescente com os quantis. Isso implica que, após o desconto da corrupção, as firmas nos quantis superiores empregam o recurso humano qualificado com maior eficiência, obtendo maior retorno no seu desempenho (vendas). Esse padrão é observado nos dois estimadores, sugerindo que a mudança no método não alterou a relação entre as variáveis, sendo apenas influente na magnitude do custo da corrupção.

Ao contrário disso, o coeficiente de elasticidade do capital apresentou inversão, de forma que o estimador de Koenker e Bassett sinaliza para uma tendenciosidade na relação entre as variáveis, caso os efeitos de endogeneidade não sejam devidamente controlados. Nesse caso, a elasticidade final dos investimentos em bens de capital demonstrou ser crescente nos quantis, após o desconto da corrupção percebida como gravíssimo obstáculo. Esse fato aponta que as firmas com baixo volume de vendas obtêm menores resultados na aplicação desses investimentos após o efeito perceptivo da corrupção.

Tomando as regressões na média da distribuição, os instrumentos empregados satisfizeram os critérios desejados: rejeição da hipótese nula na estatística de Kleibergen e Paap (2006) e não rejeição no teste J de Hansen (instrumentos válidos e relevantes).

Por fim, pode-se inferir que a corrupção tem demonstrado impacto heterogêneo na realidade brasileira. Esse impacto vem sendo mais limitante nas firmas com baixa performance. Nessa perspectiva, a hipótese da "areia na engrenagem" tornou-se mais evidente, de forma que as firmas situadas nos quantis superiores apresentam melhores condições de adaptação à presença da corrupção em relação àquelas nos quantis inferiores e, por essa razão, menores custos associados à presença da corrupção. Essa sugestão dos resultados indica a necessidade de aprofundamento desta aná- 
lise, compreendendo melhor os efeitos da corrupção em séries financeiras.

Esses resultados podem ajudar a explicar parcialmente as restrições no desenvolvimento das regiões, quando a corrupção tem se apresentado como fator limitante no processo de convergência. Corroborando com Ferraz e Finan (2011), o contexto da corrupção no Brasil torna-se uma preocupação global, de maneira que os custos da prática predatória vão muito além das "cifras" estimadas, afetando a confiança nas nossas instituições públicas num cenário favorável ao desenvolvimento sustentável.

Embora os resultados obtidos neste estudo apontem possíveis explicações sobre os efeitos da corrupção no Brasil, as conclusões alcançadas são preliminares. Pesquisas que venham trabalhar indicadores alternativos sobre corrupção são necessárias para compreender melhor os efeitos nefastos da corrupção na realidade brasileira.

\section{Referências}

ACEMOGLU, D. et al. Distance to Frontier, Selection and Economic Growth. Journal of the European Economic Association, v. 4, n. 1, p. 37-74, 2006.

AGHION, P.; HOWITT, P. The Economics of Growth. Cambridge, Massachusetts: The MIT Press, 2009.

ANDREWS, D.; BUCHINSKY, M. Evaluation of a Three-Step Method for Choosing the Number of Bootstrap Repetitions. Journal of Econometrics, v. 103, n. 1-2, p. 345-386, 2001.

ANG, J. B. et al. The Effects of Human Capital Composition on Technological Convergence. Journal of Macroeconomics, v. 33, p. 465-476, 2011.

ASIEDU, E.; FREEMAN, J. The Effect of Corruption on Investment Growth: Evidence from Firms in Latin America, Sub-Saharan Africa, and Transition Countries. Review of Development Economics, v. 13, n. 2, p. 200-214, 2009.

AYYAGARI, M. et al. Bribe Payments and Innovation in Developing Countries: Are Innovating Firms Disproportionately Affected? Journal of Financial and Quantitative Analysis, v. 49, n. 1, p. 51-75, 2014.

BASU, S.; MEHRA, M. K. Endogenous Human Capital Formation, Distance to Frontier and growth. Research in Economics, v. 68, n. 2, p. 117-132, 2014.

BOLOGNA, J.; ROSS, A. Corruption and Entrepreneurship: Evidence from Brazilian municipalities. Public Choice, v. 165, n. 1, p. 59-77, 2015.

CARRARO, A. et al. Does Governmental Corruption Affect Entrepreneurship in Brazil? Ensaios FEE, v. 37, n. 3, p. 615-642, 2016.

CASELLI, F.; COLEMAN, W. J. The World Technology Frontier. American Economic Review, v. 96, n. 3, p. 499-522, 2006. 
CHERNOZHUKOV, V.; HANSEN, C. Instrumental Variable Quantile Regression: A Robust Inference Approach. Journal of Econometrics, v. 142, n. 1, p. 379-398, 2008.

CLAUSEN, B. et al. Corruption and Confidence in Public Institutions: Evidence from a Global Survey. World Bank Economic Review, v. 25, n. 2, p. 212-249, 2011.

$\mathrm{COAD}, \mathrm{A}$. Appropriate Business Strategy for Leaders and Laggards. Industrial and Corporate Change, v. 20, n. 4, p. 1049-1079, 2011.

DI MARIA, C.; LAZAROVA, E. A. Migration, Human Capital Formation, and Growth: An Empirical Investigation. World Development, v. 40, n. 5, p. 938-955, 2012.

EFRON, B. Bootstrapping Methods: Another Look at the Jackknife. Annals of Statistics, v. 7, n. 1, p. 1-26.1979.

FERRAZ, C.; FINAN, F. Electoral Accountability and Corruption: Evidence from the Audits of Local Governments. American Economic Review, v. 101, n. 4, p. 1274-1311, 2011.

GODINEZ, J. R.; LIU, L. Corruption Distance and FDI Flows into Latin America. International Business Review, v. 24, n. 1, p. 33-42, 2015.

HEBOUS, S.; LIPATOV, V. A Journey from a Corruption Port to a Tax Haven. Journal of Comparative Economics, v. 42, n. 3, p. 739-754, 2014.

JIANG, T.; NIE, H. The Stained China Miracle: Corruption, Regulation, and Firm Performance. Economics Letters, v. 123, p. 366-369, 2014.

KLEIBERGEN, F.; PAAP, R. Generalized Reduced Rank Tests Using the Singular Value Decomposition. Journal of Econometrics, v. 133, n. 1, p. 97-126, 2006.

KOENKER, R.; BASSETT, G. Regression Quantiles. Econometrica, v. 46, p. 33-50, 1978.

KUNICOVÁ, J.; ROSE-ACKERMAN, S. Electoral Rules and Constitutional Structures as Constraints on Corruption. In: KORNAI, J. et al. Corruption, Development and Institutional Design. New York: Palgrave Macmillan, 2009.

LAMBSDORFF, J. G. The Institutional Economics of Corruption and Reform: Theory, Evidence, and Policy. New York: Cambridge University Press, 2007.

LUI, F. An Equilibrium Queuing Model of Bribery. Journal of Political Economy, v. 93, n. 4, p. 760-781.1985.

MELO, F. L. N. B. et al. Corrupção burocrática e empreendedorismo: uma análise empírica dos estados brasileiros. Revista de Administração Contemporânea, v. 19, n. 3, p. 374-397, 2015.

MEON, P.; WEILL, L. Is Corruption an Efficient Grease? World Development, v. 38, n. 3, p. 244-259, 2010.

NISHIJIMA, M. et al. Efeitos da descentralização da saúde básica no Brasil sobre o nível de corrupção em municípios investigados pelo governo central. Nova Economia, v. 27, n. 1, 2017.

OKADA, K.; SAMRETH, S. The Effect of Foreign Aid on Corruption: A Quantile Regression Approach. Economics Letters, v. 115, n. 2, p. 240-243, 2012.

ROCHA, L. A.; DAL-POZ, M. E.; SILVEIRA, J. M. F. J. Crescimento econômico e a interação entre capital humano e grau de desenvolvimento tecnológico dos países. Estudos Econômicos, Ministério da Fazenda. Texto n. 12, 2, 2013. 
SVENSSON, J. Eight Questions about Corruption. Journal of Economic Perspectives, v. 19, n. 3, p. 19-42, 2005.

WANG, Y.; YOU, J. Corruption and Firm Growth: Evidence from China. China Economic Review, v. 23, p. 415-433, 2012.

ZHANG, C.; ZHUANG, L. The Composition of Human Capital and Economic Growth: Evidence from China Using Dynamic Panel Data Analysis. China Economic Review, v. 22, n. 1, p. 165-171, 2011.

\section{Sobre os autores}

Leonardo Andrade Rocha - leonardoandrocha@yahoo.com.br Universidade Federal Rural do Semi-Árido (UFERSA), Mossoró, Rio Grande do Norte, Brasil. ORCID: https://orcid.org/0000-0003-2777-0702.

Ahmad Saeed Khan-saeed@ufc.br

Universidade Federal do Ceará (UFC), Fortaleza, Ceará, Brasil. ORCID: https://orcid.org/0000-0002-4079-7574.

Patrícia Verônica Pinheiro Sales Lima-patricialima@ufc.br Universidade Federal do Ceará (UFC), Fortaleza, Ceará, Brasil. ORCID: https://orcid.org/0000-0002-6622-3640.

Maria Ester Soares Dal Poz - ester.dalpoz@fca.unicamp.br

Universidade Estadual de Campinas (UNICAMP), Campinas, São Paulo, Brasil. ORCID: https://orcid.org/0000-0002-6871-8428

Fernando Porfirio Soares de Oliveira - fernandoporfiri@ufersa.edu.br Universidade Federal Rural do Semi-Árido (UFERSA), Mossoró, Rio Grande do Norte, Brasil. ORCID: https://orcid.org/0000-0001-7103-6340.

\section{Sobre 0 artigo}

Recebido em 02 de outubro de 2016. Aprovado em 05 de outubro de 2017. 